\title{
Simultaneous duodenal stenting and endoscopic ultrasound-guided hepatico- gastrostomy using a forward-oblique view echoendoscope
}

A 65-year old man with advanced pancreatic cancer with a combination of malignant biliary obstruction and gastric outlet obstruction was referred to our hospital. Given the presence of periampullary cancerous lesions, the endoscopic placement of a duodenal stent and endoscopic ultrasound (EUS)-guided hepaticogastrostomy (HGS) were performed simultaneously, using a single convex-array echoendoscope with a forward-oblique view (EG-580T; Fujifilm, Tokyo, Japan; Fig.1). A partially covered metal duodenal stent (Niti-S COMVI; Taewoong Medical, Gimpo, Korea) was placed under fluoroscopic and endoscopic guidance ( $\triangleright$ Fig. 2 , $\triangleright$ Video 1 ). This was followed, without scope ex-

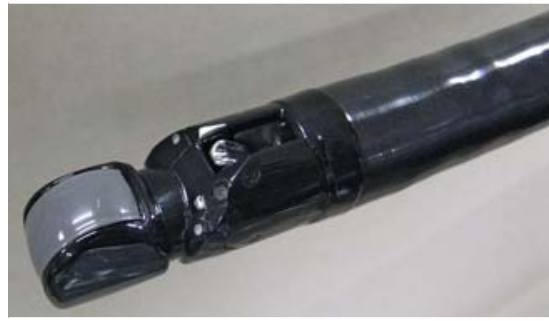

- Fig. 1 The new forward-oblique view convex-array echoendoscope, with $40^{\circ}$ forward viewing direction.

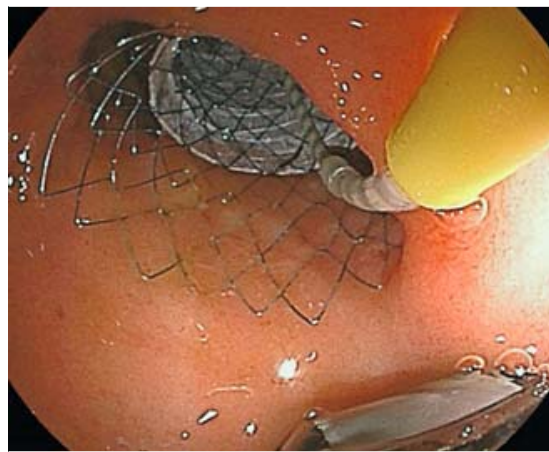

- Fig. 2 Duodenal stent placement, using the new forward-oblique view echoendoscope, in a patient with advanced pancreatic cancer and a combination of malignant biliary obstruction and gastric outlet obstruction. change, by EUS-HGS: a long partially covered metal stent (modified GIOBOR, Taewoong Medical) was successfully placed [1] from the B3 intrahepatic duct to the stomach under EUS, endoscopic, and fluoroscopic guidance
( $\triangleright$ Fig. 3, $\triangleright$ Video 2 ). The total procedure time was 38 minutes.

Combined malignant biliary obstruction and gastric outlet obstruction are not rare in advanced pancreatic cancer and EUS-guided biliary drainage, especially

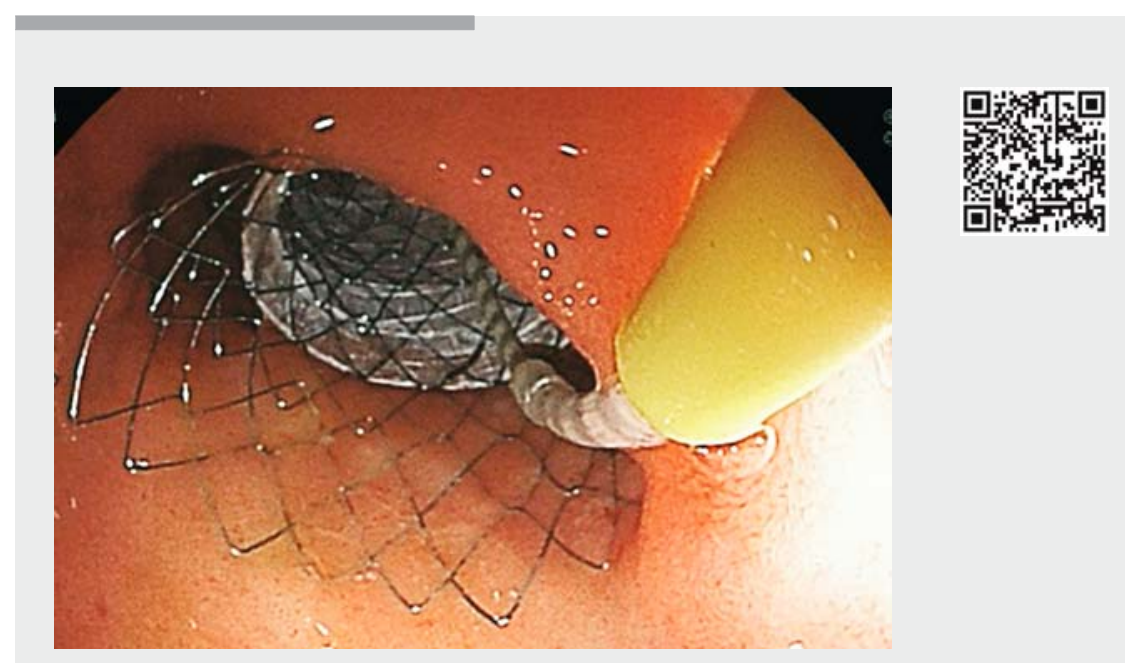

Video 1 Part 1. Simultaneous duodenal stenting and endoscopic ultrasound-guided hepaticogastrostomy (EUS-HGS) using a forward-oblique view echoendoscope. A partially covered metal duodenal stent is placed under fluoroscopic and endoscopic guidance.

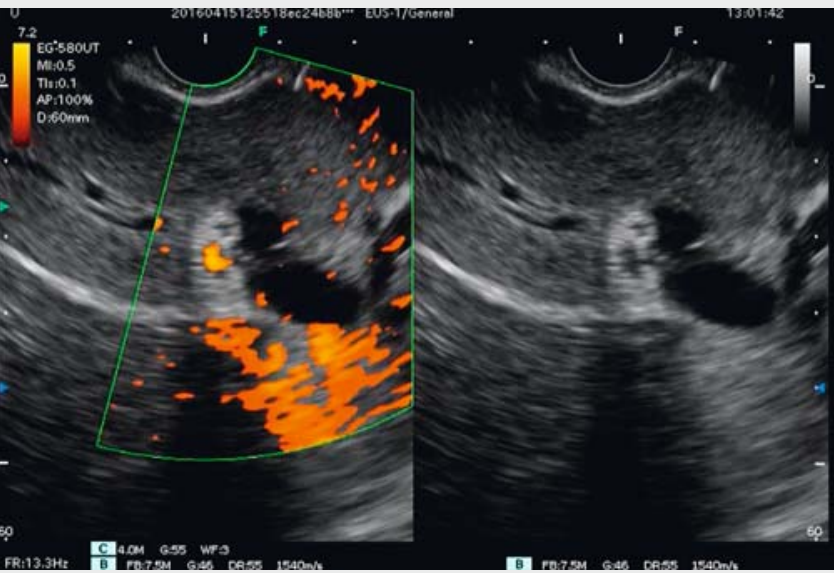

$\checkmark$ Video 2 Part 2. Simultaneous duodenal stenting and endoscopic ultrasound-guided hepaticogastrostomy (EUS-HGS). In the subsequent (EUS-HGS), done without scope exchange, a long partially covered metal stent is deployed from the B3 intrahepatic duct to the stomach under EUS, endoscopic, and fluoroscopic guidance. 


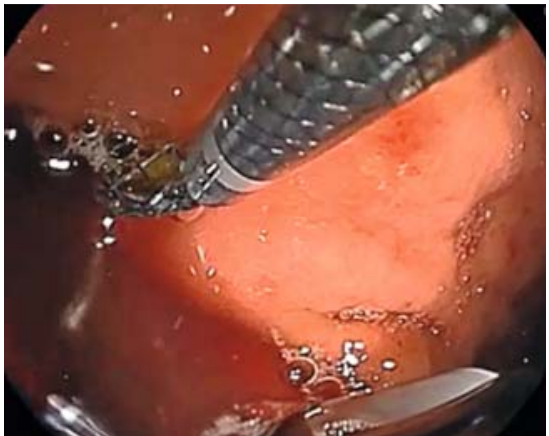

- Fig. 3 Endoscopic ultrasound-guided hepaticogastrostomy (EUS-HGS) performed, without scope exchange, immediately after the duodenal stent placement shown in $>$ Fig. 2 . The tip of the echoendoscope and the puncture site were seen endoscopically, enabling stent insertion and deployment under direct visualization.

EUS-HGS [2], is increasingly reported because of its better patency than transpapillary biliary drainage [3]. Conventionally, enteric stents are placed using a forward-viewing endoscope and EUS-guided biliary drainage by an oblique-viewing echoendoscope. A single-session dualstent placement using two endoscopes has been described [4].

This new echoendoscope with a forwardoblique view has a $3.8-\mathrm{mm}$ operating channel, and has a $40^{\circ}$ forward viewing direction with $140^{\circ}$ field of view compared to the $55^{\circ}$ viewing direction and $100^{\circ}$ field of view in the conventional obliqueviewing echoendoscope [5]. This enables the direct visualization of both the enteric stricture and the enteric stent deployment, and also helps hepaticogastrostomy with EUS-guided biliary drainage stent deployment with endoscopic guidance. Thus a single echoendoscope can be used to place a duodenal stent and an EUS-guided biliary drainage stent.
In conclusion, the simultaneous placement of a duodenal stent and EUS-HGS is feasible using the new forward-oblique view echoendoscope, facilitating shorter procedure time without the need for scope exchange.

Endoscopy_UCTN_Code_TTT_1AS_2AD

\section{Competing interests}

Hiroyuke Isayama and Yousuke Nakai have financial relationships with Fujifilm Corp. in the form of research support and/or honoraria.

\section{The Authors}

\section{Tanyaporn Chantarojanasiri ${ }^{1,2}$, Hiroyuki} Isayama', Yousuke Nakai', Saburo

Matsubara ${ }^{1}$, Suguru Mizuno ${ }^{1}$, Hirofumi Kogure $^{1}$, Kazuhiko Koike ${ }^{1}$

1 Department of Gastroenterology, the University of Tokyo, Tokyo, Japan

2 Department of Internal Medicine, Police General Hospital, Bangkok, Thailand

\section{Corresponding author}

\section{Hiroyuki Isayama, MD, PhD}

Department of Gastroenterology, Graduate School of Medicine, The University of Tokyo, 7-3-1 Hongo, Bunkyo-ku, Tokyo 113-8655, Japan

Fax: +81-3-3814-0021

isayama-tky@umin.ac.jp

\section{References}

[1] Nakai $Y$, Isayama $\mathrm{H}$, Yamamoto $\mathrm{N}$ et al. Safety and effectiveness of a long, partially covered metal stent for endoscopic ultrasound-guided hepaticogastrostomy in patients with malignant biliary obstruction.
Endoscopy 2016; 48: 1125-1128. Epub 2016 Oct 7

[2] Ogura T, Chiba Y, Masuda D et al. Comparison of the clinical impact of endoscopic ultrasound-guided choledochoduodenostomy and hepaticogastrostomy for bile duct obstruction with duodenal obstruction. Endoscopy 2016; 48: $156-163$

[3] Hamada T, Isayama H, Nakai Y et al. Transmural biliary drainage can be an alternative to transpapillary drainage in patients with an indwelling duodenal stent. Dig Dis Sci 2014; 59: 1931 - 1938

[4] Kawakubo K, Isayama H, Nakai Y et al. Simultaneous duodenal metal stent placement and EUS-guided choledochoduodenostomy for unresectable pancreatic cancer. Gut Liver 2012; 6: 399-402

[5] Murad FM, Komanduri S, Abu Dayyeh BK et al. Echoendoscopes. Gastrointest Endosc 2015; 82: 189-202

\section{Bibliography}

DOI https://doi.org/10.1055/s-0043-116379

Published online: 5.9.2017

Endoscopy 2017; 49: 1109-1110

(c) Georg Thieme Verlag KG

Stuttgart · New York

ISSN 0013-726X

\section{ENDOSCOPY E-VIDEOS}

https://eref.thieme.de/e-videos

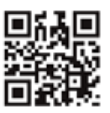

Endoscopy E-Videos is a free access online section, reporting on interesting cases and new techniques in gastroenterological endoscopy. All papers include a high quality video and all contributions are freely accessible online.

This section has its own submission website at https://mc.manuscriptcentral.com/e-videos 